\title{
BILANGAN TERHUBUNG TITIK PELANGI PADA AMALGAMASI GRAF BERLIAN
}

\author{
Afifah Farhanah Akadji ${ }^{*}$, Dennynatalis Taha ${ }^{2}$, Narti Lakisa ${ }^{3}$, Nisky Imansyah Yahya ${ }^{4}$ \\ 1,2,3,4Jurusan Matematika, Universitas Negeri Gorontalo, Bone Bolango 96119, Indonesia \\ *Penulis Korespondensi. Email: farhanah.akadji@gmail.com
}

\begin{abstract}
Abstrak
Misalkan terdapat suatu graf sederhana, terbatas, dan berhingga $G=(V, E)$. Pewarnaan titik $c$ dinotasikan dengan $c: E(G) \rightarrow\{1,2, \ldots, k\}$ dengan $k$ banyaknya pewarnaan pelangi pada graf $G$. Suatu graf dikatakan terhubung pelangi apabila setiap pasang titik $x$ dan $y$ terdapat lintasan pelangi. Sebuah lintasan dikatakan pelangi apabila tidak terdapat dua buah sisi yang memiliki warna yang sama dalam satu lintasan. Bilangan terhubung pelangi graf $G$ dinotasikan dengan $r c(G)$ adalah bilangan bulat positif terkecil- $k$ yang membuat graf $G$ memiliki pewarnaan pelangi. Selanjutnya, graf dikatakan terhubung titik pelangi apabila pada setiap pasang titik $x$ dan $y$ tidak terdapat dua buah titik yang memiliki warna yang sama dalam satu lintasan. Bilangan terhubung titik pelangi graf $G$ dinotasikan dengan $\operatorname{rvc}(G)$ adalah bilangan bulat positif terkecil- $k$ yang membuat graf $G$ memiliki pewarnaan pelangi. Pada makalah ini dibahas tentang bilangan terhubung titik pelangi pada amalgamasi graf berlian. Graf berlian dengan $2 n$ titik dinotasikan dengan $B r_{n}$ dan amalgamasi graf berlian $B r_{n}$ dengan menambahkan penggandaan graf sebanyak t pada titik v dinotasikan dengan $\operatorname{Amal}\left(B r_{n}, v, t\right)$.
\end{abstract}

Kata Kunci: Bilangan Terhubung Titik Pelangi; Amalgamasi; Graf Berlian

\begin{abstract}
Suppose there is a simple, and finite graph $G=(V, E)$. The coloring of vertices $c$ is denoted by $c$ : $E(G) \rightarrow\{1,2, \ldots, k\}$ with $k$ is the number of rainbow colors on graph $G$. A graph is said to be rainbow connected if every pair of points $x$ and $y$ has a rainbow path. A path is said to be a rainbow if there are not two edges that have the same color in one path. The rainbow connected number of graph $G$ denoted by $r c(G)$ is the smallest positive integer-k which makes graph $G$ has rainbow coloring. Furthermore, a graph is said to be connected to rainbow vertex if at each pair of vertices $x$ and $y$ there are not two vertices that have the same color in one path. The rainbow vertex connected number of graph $G$ is denoted by rvc $(G)$ is the smallest positive integer-k which makes the graph $G$ has rainbow coloring. This paper discusses rainbow vertex connected number in the amalgamation of a diamond graph. A diamond graph with $2 n$ points is denoted by $B r_{n}$ and amalgamation of a diamond graph $B r_{n}$ by adding the multiplication of the graph $t$ at point $v$ is denoted by Amal $\left(B r_{n}, v, t\right)$.
\end{abstract}

Keywords: Rainbow Vertex Connected Number; Amalgamation; Diamond Graph

\section{Pendahuluan}

Teori graf adalah salah satu cabang ilmu matematika yang mempelajari tentang sifat-sifat graf. Graf yang digunakan untuk merepresentasikan objek-objek diskrit pada matematika memiliki beberapa operasi seperti penjumlahan graf, perkalian graf, dan amalgamasi [1]. Amalgamasi merupakan penggandaan graf yang dipusatkan pada satu elemen dari graf tersebut [2].

Seiring perkembangannya, topik penelitian cabang teori graf semakin luas. Salah satu topiknya yaitu bilangan terhubung pelangi. Bilangan terhubung pelangi pertama kali diperkenalkan oleh seorang matematikawan bernama Chartrand pada tahun 2008 [3]. Pada tahun 2009, topik bilangan terhubung pelangi ini kemudian dikembangkan oleh Krivelevich dan Yuster [4] yang 
memperkenalkan bilangan terhubung titik pelangi yang merupakan bilangan terkecil yang dapat membuat sebuah graf memiliki lintasan pelangi pada setiap pasang titiknya. Diameter merupakan jarak terbesar dari seluruh pasang titik yang dinotasikan dengan $\operatorname{diam}(G)$. Misalkan $m$ merupakan banyaknya titik pada graf $G$, sehingga

$$
\operatorname{diam}(G)-1 \leq \operatorname{rvc}(G) \leq m-2
$$

Pada penelitian sebelumnya, telah diteliti bilangan terhubung pelangi pada graf berlian $\left(B r_{n}\right)$ yang diteliti oleh Shulhany dan Salman [5]. Dengan menggunakan operasi amalgamasi pada graf berlian $\left(B r_{n}\right)$, penelitian ini akan membahas bilangan terhubung titik pelangi pada amalgamasi graf berlian $\left(B r_{n}\right)$.

\section{Metode Penelitian}

Penelitian ini menggunakan metode penelitian studi literatur (library research). Pada penelitian ini dilakukan kajian terhadap buku, textbook, jurnal, dan artikel-artikel ilmiah mengenai amalgamasi dan graf berlian. Adapun langkah-langkah yang dilakukan adalah

1. Menggambar bentuk amalgamasi graf berlian

2. Menentukan pewarnaan titik amalgamasi graf berlian, dan

3. Membuktikan teorema

\section{Hasil dan Pembahasan}

Graf berlian dinotasikan dengan $B r_{n}$ dengan definisi sisi dan titik sebagai berikut:

$$
\begin{aligned}
V\left(B r_{n}\right)= & \{v\} \cup\left\{v_{i} \mid i \in\{1,2, \ldots, n\}\right\} \cup\left\{u_{i} \mid i \in\{1,2, \ldots n-1\}\right\} \\
E\left(B r_{n}\right)= & \left\{v v_{i} \mid i \in\{1,2, \ldots, n\}\right\} \cup\left\{v_{i} v_{i+1} \mid i \in\{1,2, \ldots, n-1\}\right\} \cup\left\{u_{i} u_{i+1} \mid i \in\{1,2, \ldots, n-2\}\right\} \\
& \cup\left\{u_{i} v_{i} \mid i \in\{1,2, \ldots, n-1\}\right\} \cup\left\{u_{i} v_{i-1} \mid i \in\{1,2, \ldots, n-1\}\right\}
\end{aligned}
$$

Amalgamasi graf berlian $\left(B r_{n}\right)$ sebanyak $t$ dengan $v$ adalah titik terminal dinotasikan dengan $\operatorname{Amal}\left(B r_{n}, v, t\right)$ dengan $n \geq 4 . \operatorname{Amal}\left(B r_{n}, v, t\right) \quad$ memiliki diameter $=\operatorname{diam}(G)=4$ dan didefinisikan oleh:

$$
\begin{aligned}
& V\left(\operatorname{Amal}\left(B r_{n}, v, t\right)\right)=\left\{\begin{array}{cc}
u_{i, j}, \quad i \in[1, t] \quad j \in[1, n-1] \\
v_{i, j}, i \in\{1, t] \quad j \in[1, n] \\
v \quad i \in[1, t], \quad j \in[1, n-2]
\end{array}\right. \\
& E\left(\operatorname{Amal}\left(B r_{n}, v, t\right)\right)=\left\{\begin{array}{ccc}
u_{i, j} u_{i, j+1} ; & i \in[1, n-1] \\
v_{i, j} v_{i, j+1} ; & i \in[1, t] & j \in[1, n \in[1, n-1] \\
u_{i, j} v_{i, j} ; & i \in[1, t], & j \in[1, n-1, n-1] \\
u_{i, j} v_{i, j+1} ; & i \in[1, t], & j \in[1, n-1, n] \\
v_{i, j} v ; & i \in[1, t], & j \in[1, n]
\end{array}\right.
\end{aligned}
$$

Gambar graf berlian $\mathrm{Br}_{4}$ dan $\mathrm{Amal}\left(\mathrm{Br}_{4}, v, 2\right)$ berturut-turut ditunjukkan pada Gambar 1 dan Gambar 2. 


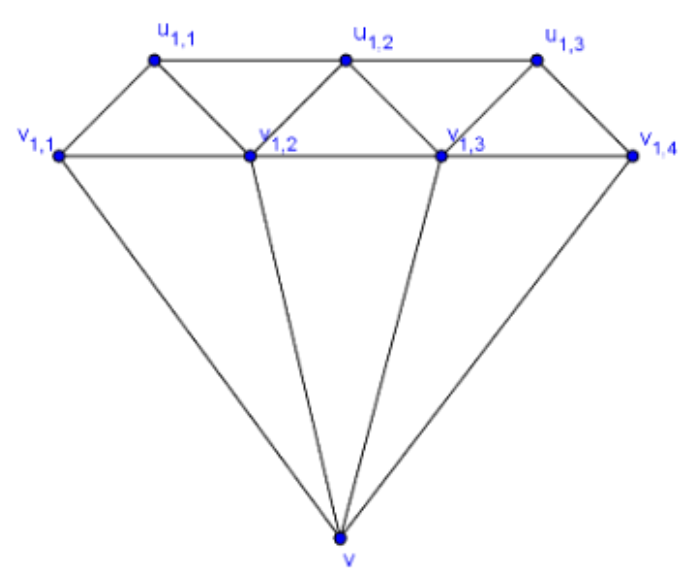

Gambar 1. Graf Berlian $\mathrm{Br}_{4}$

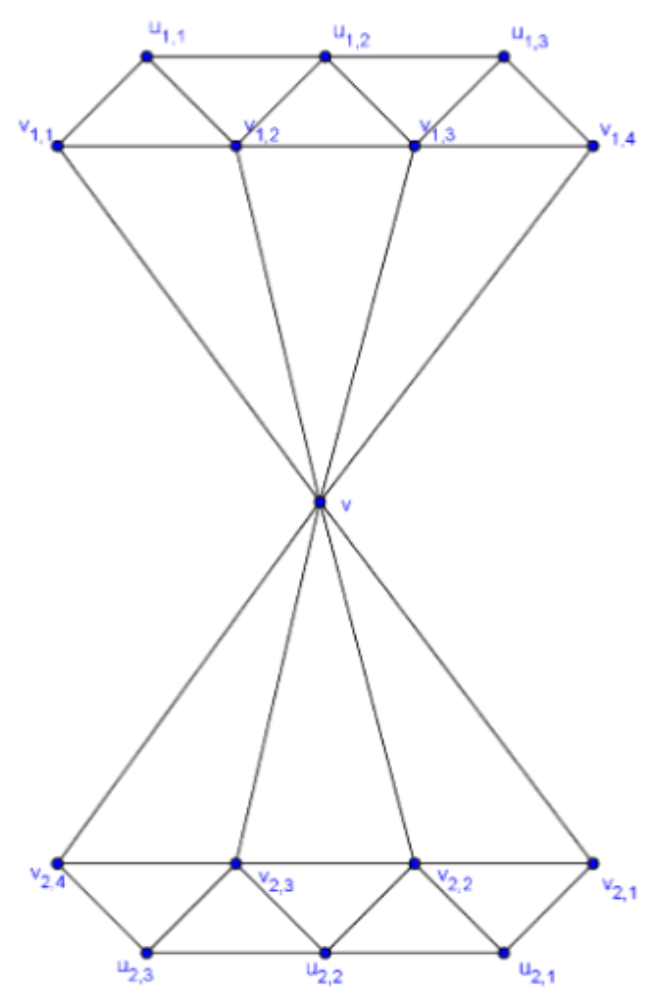

Gambar 2. $\mathrm{Amal}\left(\mathrm{Br}_{4}, v, 2\right)$

\section{Teorema 1}

Misalkan $G \cong \operatorname{Amal}\left(B r_{n}, v, t\right)$ dengan bilangan bulat $n \geq 4$ dan $t \geq 2$. Maka bilangan terhubung titik pelangi adalah

$$
\operatorname{rvc}(G)=\operatorname{diam}(G)=4
$$

\section{Bukti:}

Definisikan pewarnaan $c: E(G) \rightarrow\{1,2,3,4\}$ sebagai berikut: 


$$
c(E(G))=\left\{\begin{array}{clc}
u_{i, j}=(j+1) \bmod 2+1 ; & i \in[1, t], & j \in[1, n-1] \\
v_{i, j}=j \bmod 2+3 ; & i \in[1, t], & j \in[2, n] \\
v_{i, 1}=2 ; & i \in[1, t], & \\
v=1 ; &
\end{array}\right.
$$

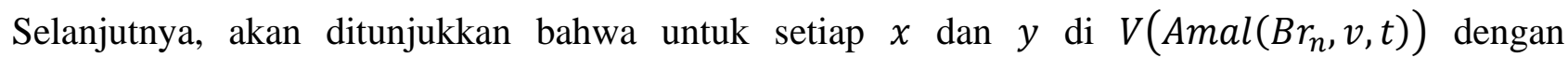
$\operatorname{diam}(x, y) \geq 3$, terdapat lintasan pelangi $x-y$.

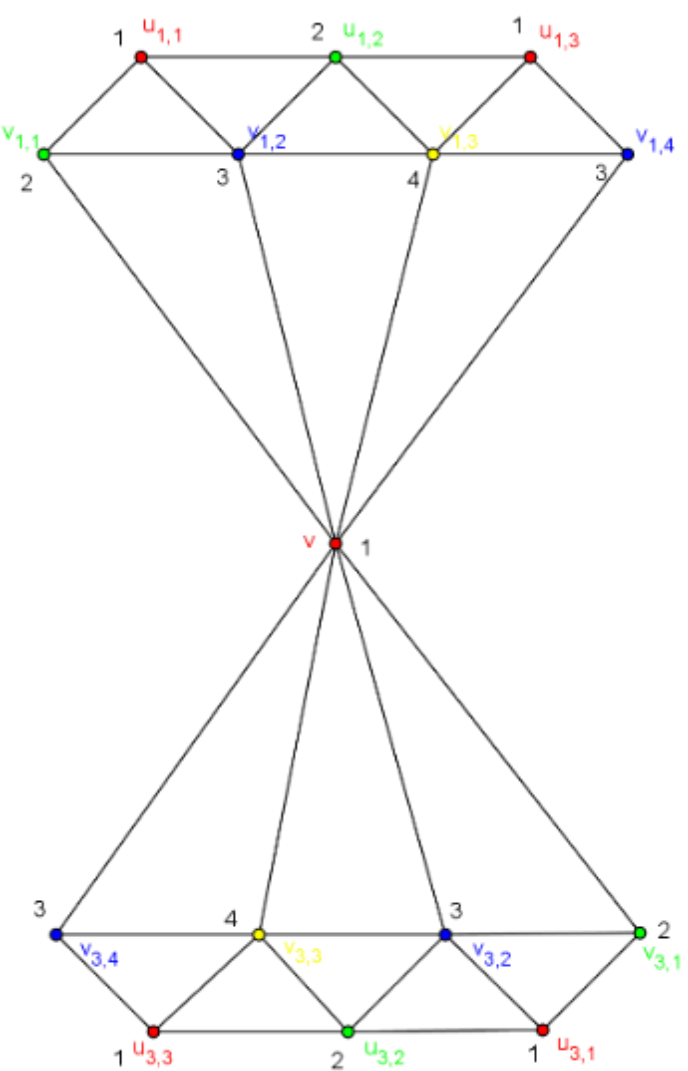

Gambar 3. Pewarnaan pelangi $\mathrm{Amal}\left(\mathrm{Br}_{4}, v, 2\right)$

Kasus 1. Untuk $i \in[1, t]$, dan $j \in[1, n-4]$, Jika $x=u_{i, j}$ dan $y=u_{i, j+3}$, untuk $n \geq 5$, maka terdapat lintasan $u_{i, j}, u_{i, j+1}, u_{i, j+2}, u_{i, j+3}$.

Kasus 2. Untuk $i \in[1, t]$, dan $j \in[1, n-5]$, Jika $x=u_{i, j}$ dan $y=u_{i, j+4}$, untuk $n \geq 6$, maka terdapat lintasan $u_{i, j}, u_{i, j+1}, u_{i, j+2}, u_{i, j+3}, u_{i, j+4}$.

Kasus 3. Untuk $i \in[1, t]$, dan $j, k \in[1, n]$ dengan $j<k$, Jika $x=u_{i, j}$ dan $y=v_{i, k}$, maka terdapat lintasan $u_{i, j}, v_{i, j}, v, v_{i, k}$.

Kasus 4. Untuk $i \in[1, t-1], k \in[i+1, t]$, dan $j, l \in[1, n-1]$

Subkasus 4.1. Jika $x=u_{i, j}$ dan $y=v_{k, l}$, maka terdapat lintasan $u_{i, j}, v_{i, j}, v, v_{k, l}$.

Subkasus 4.2. Jika $x=v_{i, j}$ dan $y=u_{k, l}$, maka terdapat lintasan $v_{i, j}, v, v_{k, l}, u_{k, l}$.

Kasus 5. Untuk $i \in[1, t-1], k \in[i+1, t]$, dan $j, l \in[1, n-1]$ 
Subkasus 5.1. Jika $x=u_{i, j}$ dan $y=u_{k, l}$, dengan $j$ dan $l$ memiliki varitas yang sama maka terdapat lintasan $u_{i, j}, v_{i, j}, v, v_{k, l+1}, u_{k, l}$.

Subkasus 5.2. Jika $x=u_{i, j}$ dan $y=u_{k, l}$, dengan $j$ dan $l$ memiliki varitas yang berbeda maka terdapat lintasan $u_{i, j}, v_{i, j}, v, v_{k, l}, u_{k, l}$.

Kasus 6. Untuk $i \in[1, t]$ dan $j, k \in[1, n-1]$ dengan $j<k$, untuk $n \geq 6$, maka terdapat lintasan $u_{i, j}, v_{i, j}, v, v_{i, k}, u_{i, k}$.

Graf hasil pewarnaan masing-masing ditampilkan pada Gambar 3, Gambar 4, dan Gambar 5.

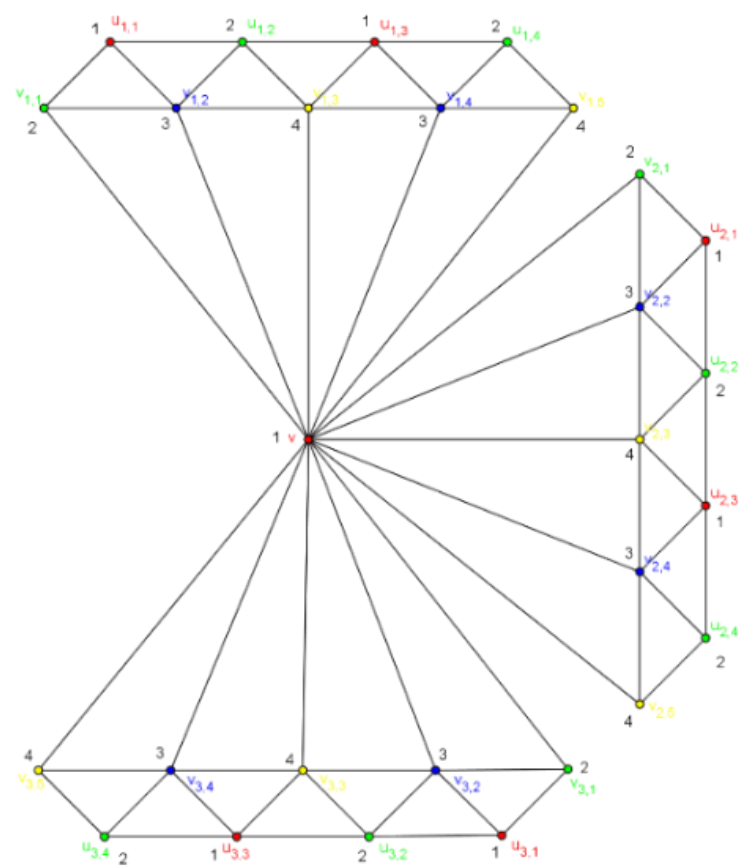

Gambar 4. Pewarnaan pelangi Amal $\left(\mathrm{Br}_{5}, v, 3\right)$

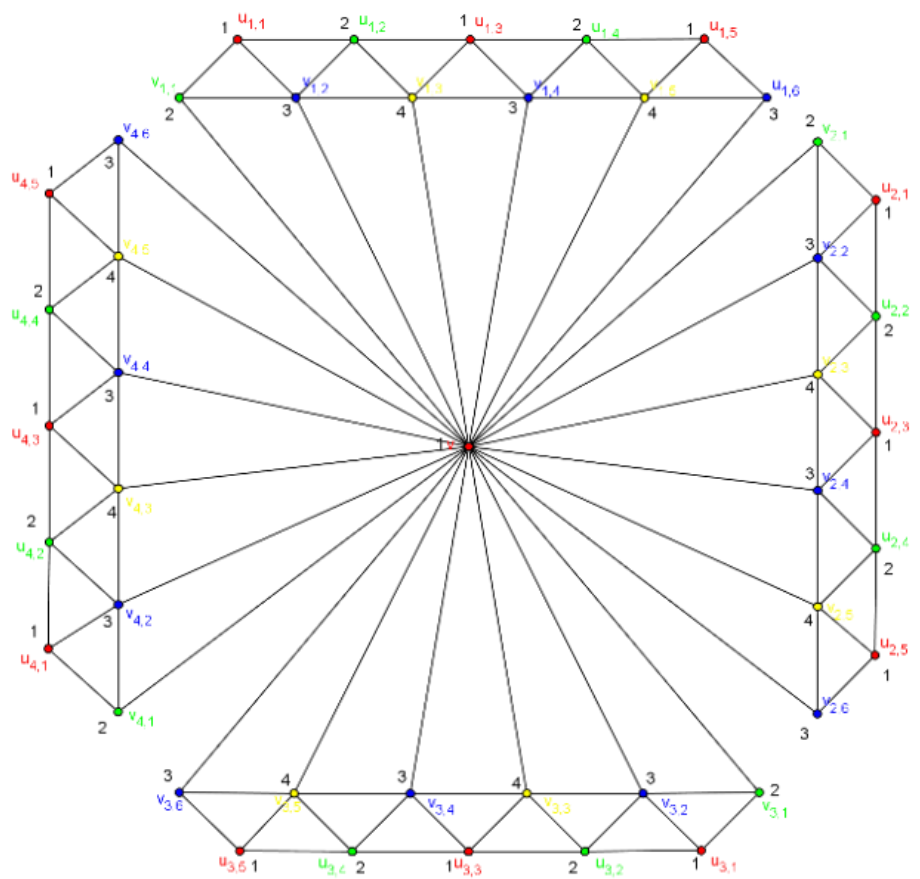

Gambar 4. Pewarnaan pelangi $\operatorname{Amal}\left(\mathrm{Br}_{6}, v, 4\right)$ 


\section{Kesimpulan}

Bilangan terhubung titik pelangi untuk amalgamasi graf berlian $\operatorname{Amal}\left(B r_{n}, v, t\right)$ sama dengan diameter graf. Sehingga, diperoleh bilangan terhubung titik pelangi pada amalgamasi graf berlian yaitu

$$
\operatorname{rvc}\left(\operatorname{Amal}\left(B r_{n}, v, t\right)\right)=\operatorname{diam}(G)=4
$$

\section{Referensi}

[1] Hasmawati, "Dekomposisi Graf Hasil Kali Tiga Lintasan ke Dalam Sub Graf Perentang Reguler," J. Mat. Stat. dan Komputasi, vol. 10, no. 1, pp. 14-25, 2013.

[2] J. L. Gross, I. F. Khan, and M. I. Poshni, "Genus Distribution of Graph Amalgamations: Pasting at Root-Vertices," ars Comb., vol. 94, pp. 33-353, 2010.

[3] G. Chartrand et al., "RAINBOW CONNECTION IN GRAPHS," J. Comb. Math. Comb. Comput., vol. 1, pp. 85-98, 2008.

[4] M. Krivelevich and R. Yuster, "The Rainbow Connection of a Graph Is (at Most) Reciprocal to Its Minimum Degree Michael," J. Graph Theory, vol. 63, pp. 185-191, 2009.

[5] M. A. Shulhany and A. N. M. Salman, "Bilangan Terhubung Pelangi Graf Berlian," in Prosiding Seminar Nasional Matematika dan Pendidikan Matematika UMS, pp. 916-923, 2015. 